\title{
Depression symptoms related to undertaking regular physical activity in students of the Faculty of Physiotherapy
}

\author{
DOI: https://doi.org/10.5114/pq.2020.99753
}

\section{Joanna Szczepańska-Gieracha, Jagoda Rusowicz, Anna Markowska}

Department of Occupational Therapy, Faculty of Physiotherapy, University School of Physical Education in Wrocław, Wrocław, Poland

\section{Abstract}

Introduction. The aim of the study was to assess the frame of mind and mood of students of extramural studies at the Faculty of Physiotherapy at the University School of Physical Education in Wrocław in the context of regular physical activity.

Methods. The research involved 35 students of the second year of extramural studies (the whole year 2017/2018). Mood disorders were examined with the Beck Depression Inventory. Moreover, the respondents answered a number of questions included in a questionnaire concerning their economic situation, the possession of a loved one or a close relative, the willingness to receive help from a psychologist/psychotherapist in the case of problems, their professional plans, and undertaking physical activity.

Results. Overall, $49 \%$ of the studied group experienced mood disorders of different severity and $6 \%$ met the criteria for diagnosing depression. Lack of regular physical activity, gender, and economic situation were significantly related to the occurrence of depressive symptoms.

Conclusions. Owing to the high percentage of students with mood disorders, education in the area of prevention and treatment of depression is very important, as is access to psychological support during the course of studies. The mental condition of future physiotherapists is also crucial for the quality of their work, which is related to helping the sick and disabled.

Key words: regular physical activity, mood disorders, depression, burnout prevention

\section{Introduction}

Depression is a serious mental disorder characterized by worsening of mood, a decrease in energy and activity, as well as loss of any interests, all of which prevent proper functioning [1]. The number of people living with depression in the general population increased by $18.4 \%$ between 2005 and 2015. Today, 350 million people worldwide suffer from depression [2], with 40 million in Europe alone. Women are more likely (5.1\%) to be depressed than men (3.6\%) and the incidence of depressive disorders increases with age. It is estimated that in Poland, $5.1 \%$ of the population suffers from depression.

Why is depression becoming more and more widespread despite the prevailing prosperity, greater opportunities, better living conditions, and the increased availability of healthcare institutions? The reasons for this phenomenon can be found in abnormal lifestyle (bad eating habits, stimulants, lack of physical activity, stress, sleeping problems), dynamic development of the society (increased demands, ambitions, expectations, lack of work-life balance), prolonged life expectancy and the related health issues, stereotypes, low social awareness of mental illness, and limited availability of psychiatric medical care [3].

The positive impact of regular physical activity on human health is well known and documented. Systematic physical exercise has a beneficial effect on the cardiopulmonary system, the osteoarticular system, and the lipid profile. Physical activity helps to prevent civilization diseases, to reduce overweight, and to maintain proper body weight. Moreover, exercise is also beneficial for mental health as it reduces the level of stress by lowering the level of cortisol and increases the sense of life energy, thus leading to better mood owing to the release of endorphins [4]. Despite so many benefits, results from the 2012 Public Opinion Research Centre report [5] show that as many as $45 \%$ of respondents did not engage in any physical activity and every fifth respondent was never or almost never able to make time for a walk lasting longer than an hour. The most frequently chosen forms of relaxation were watching TV, family life activities, and passive rest (sitting, lying).

The earliest stages of adulthood are associated with achieving maturity, making life choices, and becoming independent, all of which can be a serious psychological burden and pose a particular threat to mental health [6]. University students encounter significant levels of chronic stress over quite a long time, which can trigger the development of stressrelated health problems [7]. The change in social roles that occurs after graduation may also constitute a depressive factor. These assumptions are confirmed by the increased proportion of depressed people in the higher years of study [8]. Depression also has a significant impact on the impairment of professional performance [9]. Wiraszka et al. [6] reported that, among the sociodemographic variables, the most influential factors affecting the severity of depressive symptoms in the studied group were gender and the economic status of the parents. Significantly more severe depressive symptoms were presented by girls and by students in a poor financial situation. Therefore, students in their final year of physiotherapy are the most vulnerable group with regard to the above-mentioned risk factors of depression.

The aim of the study was to assess the mood and sense of well-being among extramural students of the Faculty of Physiotherapy at the University School of Physical Educa-

Correspondence address: Jagoda Rusowicz, Department of Occupational Therapy, Faculty of Physiotherapy, University School of Physical Education in Wrocław, al. I.J. Paderewskiego 35, 51-612 Wrocław, Poland, e-mail: jagodarusowicz@gmail.com 
tion in Wrocław and to evaluate the role of regular physical activity in maintaining mental health. The following research questions were formulated:

1. What is the mood and sense of well-being of the finalyear students of extramural master studies at the Faculty of Physiotherapy of the University School of Physical Education in Wrocław?

2. Does the mood and sense of well-being of the examined students relate to regular physical activity, gender, and financial situation?

3 . Is the severity of depressive symptoms related to satisfaction with the chosen field of study and the sense of preparation for the profession and future career plans?

4. Would students accept the assistance of a psychologist/therapist in the case of problems?

\section{Subjects and methods}

The study group consisted of final-year students of the extramural master degree program in physiotherapy at the University School of Physical Education in Wrocław (all from academic year 2017/2018). The inclusion criteria were: final year of extramural studies at the Faculty of Physiotherapy and willingness to participate in the study.

The group of 35 students consisted of 28 women (80\%) and 7 men (20\%), all aged $24-39$ years. The average age of the group was 25.3 years, with a standard deviation of 2.9 years. The men were more age-differentiated and their average age was significantly higher than the average age of the women (Table 1).

Most of the participants were employed as physiotherapists $(61 \%)$ and their work experience in the profession ranged from 6 months to 4 years (Figure 1).

The majority of the respondents (94\%) were satisfied with the choice of the field of study, although only 13 (37\%) believed that the undertaken studies prepared them well to work as physiotherapists. However, all students intended to take up employment in their trained profession after graduation and $20 \%$ declared plans to go abroad.

Depressive symptoms were assessed with the Beck Depression Inventory (BDI). The Polish adaptation of the instru- ment was standardized in 1977 . The reliability and validity of BDI measurement in the control group and clinical trials was estimated. Analyses of BDI measurement validity focused on the assessment of theoretical validity (correlations with other scales examining mental disorder syndromes) and criterion validity (differences in BDI results between the control and the demographic and clinical groups). Standards for diagnosing moderate and severe depression were established. The results obtained indicate high reliability and validity of measurement for the Polish version of BDI, fully comparable with those for the original version, and the inventory is recommended for use in scientific and clinical research in Poland [10].

BDI consists of 21 questions that fall into 4 categories, assessing emotional, cognitive, motivational, and physical aspects. Each question contains 4 answers with point values (0-3 points). The respondent chooses one of the answers that best describes their mood within the previous 7 days. The maximum number of points to be obtained is 63: the greater the number of points, the more severe the symptoms. The results within the specified ranges suggest the current state of the patient. The screening scale result is not equivalent to a clinical diagnosis, but a psychological consultation is recommended for scores exceeding 11 points [11].

A basic statistical description of the obtained research material was achieved by determining average values, standard deviations, and the range of variability of the analysed characteristics. Normality of distribution of the analysed characteristics (age, level of depression in BDI) was assessed with the Shapiro-Wilk test. In the case of age, the null hypothesis of the normality of empirical distribution was not rejected. The dependence of age distribution on the gender of the examined students was determined by using parametric Student's $t$-test for independent samples. The distribution of depression level assessed by BDI was significantly different from normal $(W=0.908 ; p=0.006)$; therefore, non-parametric tests were applied to analyse the dependence of depression level on categorized variables (Mann-Whitney test for comparing 2 distributions and Kruskal-Wallis ANOVA for comparing more distributions). The null hypotheses were verified at a significance level of $p<0.05$. Statistical calcu-

Table 1. Age distribution in the study group by gender

\begin{tabular}{|l|c|c|c|c|c|c|}
\hline \multirow{2}{*}{ Group } & \multicolumn{4}{|c|}{ Age (years) } & \multicolumn{2}{c|}{ Student's $t$-test } \\
\cline { 2 - 7 } & Average & $S D$ & Minimum & Maximum & $t$ & $p$ \\
\hline Women & 24.6 & 1.1 & 24 & 28 & \multirow{2}{*}{3.43} & 0.0016 \\
\hline Men & 28.3 & 5.5 & 24 & 39 & & \\
\hline
\end{tabular}

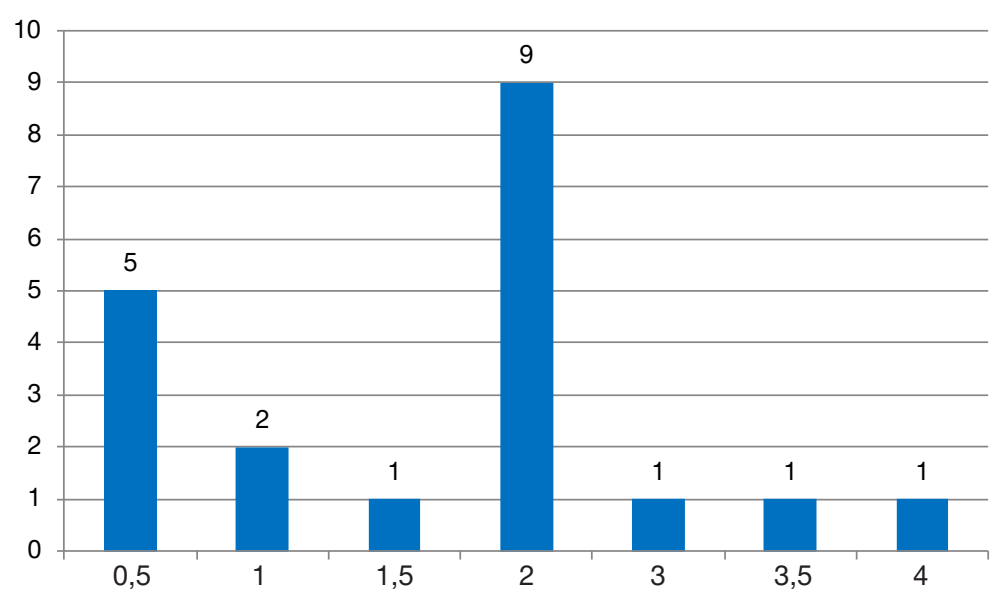


lations were carried out with the Statistica 13.1 software package.

\section{Ethical approval}

The research related to human use has complied with all the relevant national regulations and institutional policies, has followed the tenets of the Declaration of Helsinki, and has been approved by the authors' institutional review board or an equivalent committee.

\section{Informed consent}

Informed consent has been obtained from all individuals included in this study.

\section{Results}

The average level of depressive symptoms measured by BDI in the studied group was 10.7 points. In $51 \%$ of students $(\mathrm{BDI} \leq 10)$, no mood disorders were observed. In the remaining group, mood disorders of slight intensity were found in most cases (43\%) but there were also individuals with serious depressive disorders (6\%) (Figure 2).

The results for the severity of depressive symptoms assessed by BDI in the studied group differed significantly from a normal distribution, so non-parametric tests were used in the comparative analysis. Although the numbers of women and men in the investigated group differed significantly, the percentage of cases without depression was significantly higher for men (Figure 3). The gender dependence of depression was statistically significant $(p=0.01)$.

More than half of the respondents (57\%) did not engage in regular physical activity and students with mood disor- ders predominated in this group (Table 2). The correlation between lack of physical activity and the level of mood disorders was statistically significant (Figure 4).

Regular physical activity was related to gender (Figure 5).

The better the financial situation of the respondents, the lower the average level of depressive symptoms was revealed (Table 3).

After a dichotomous division of the financial situation (bad vs. satisfactory or good), the dependence of the severity of depressive symptoms on the assessment of the financial situation proved to be statistically significant (Table 4). Thus, bad financial situation was one of the key factors to reduce the respondents' level of well-being.

A total of 28 subjects ( $80 \%$ ) answered 'Yes' to the question 'Would you accept the help of a therapist in the case of personal problems?'

The majority of the respondents (94\%) were satisfied with the choice of studies, although only $13(37 \%)$ believed that the studies they had undertaken would prepare them well to work as physiotherapists. Nevertheless, all the students intended to take up employment in the profession after graduation. However, $20 \%$ declared plans to go abroad.

\section{Discussion}

The presented results provided very disturbing information about depressive symptoms in final-year students of extramural studies of the Faculty of Physiotherapy at the University School of Physical Education in Wrocław. Of the studied group, 49\% experienced mood disorders, including depressive disorders of moderate severity (3\%) and serious depressive disorders (3\%). Comparing the above data with
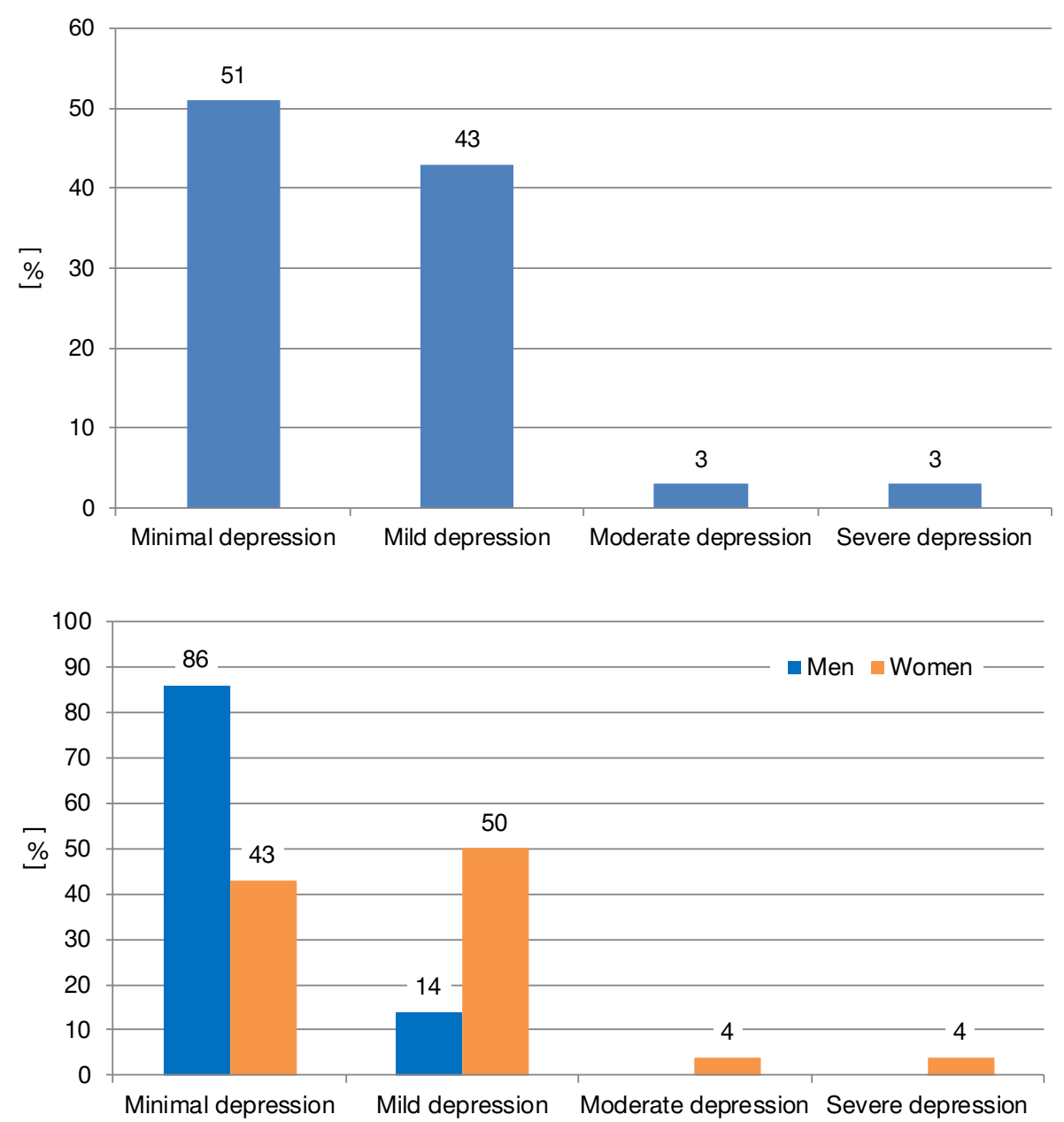

Figure 2. Distribution of depression level as evaluated by Beck Depression Inventory in the studied group $(n=35)$ 
Table 2. Undertaking physical activity and Beck Depression Inventory results in the examined group

\begin{tabular}{|c|c|c|c|c|c|c|c|}
\hline \multirow{2}{*}{ Regular physical activity } & \multirow{2}{*}{$n$} & \multicolumn{4}{|c|}{ Beck Depression Inventory (points) } & \multicolumn{2}{|c|}{ Mann-Whitney test } \\
\hline & & Average & $S D$ & Minimum & Maximum & $z$ & $p$ \\
\hline No & 20 & 12.9 & 7.2 & 2 & 35 & \multirow{2}{*}{2.03} & \multirow{2}{*}{0.043} \\
\hline Yes & 15 & 7.8 & 6.2 & 0 & 19 & & \\
\hline
\end{tabular}

Table 3. Dependence of the level of depressive symptoms on the financial situation

\begin{tabular}{|l|c|c|c|c|c|c|c|}
\hline \multirow{2}{*}{ Financial situation } & \multirow{2}{*}{$n$} & \multicolumn{3}{|c|}{ Beck Depression Inventory (points) } & \multicolumn{2}{c|}{ ANOVA (Kruskal-Wallis) } \\
\cline { 3 - 7 } & & Average & $S D$ & Minimum & Maximum & $H$ & \\
\hline Bad & 9 & 15.4 & 7.5 & 11 & 35 & \\
\hline Satisfactory & 9 & 9.8 & 5.8 & 0 & 16 & 4.50 & 0.105 \\
\hline Good & 17 & 8.7 & 6.8 & 1 & 24 & & \\
\hline
\end{tabular}

Table 4. Dependence of the level of depression as measured by the Beck Depression Inventory on the respondents' financial situation

\begin{tabular}{|l|c|c|c|c|c|c|c|}
\hline \multirow{2}{*}{ Financial situation } & \multirow{2}{*}{$n$} & \multicolumn{3}{|c|}{ Beck Depression Inventory (points) } & \multicolumn{3}{c|}{ Mann-Whitney test } \\
\cline { 3 - 7 } & & Average & $S D$ & Minimum & Maximum & $Z$ & $p$ \\
\hline Bad & 9 & 15.4 & 7.5 & 11 & 35 & 2.03 & 0.042 \\
\hline Satisfactory or good & 26 & 9.1 & 6.4 & 0 & 24 & & \\
\hline
\end{tabular}
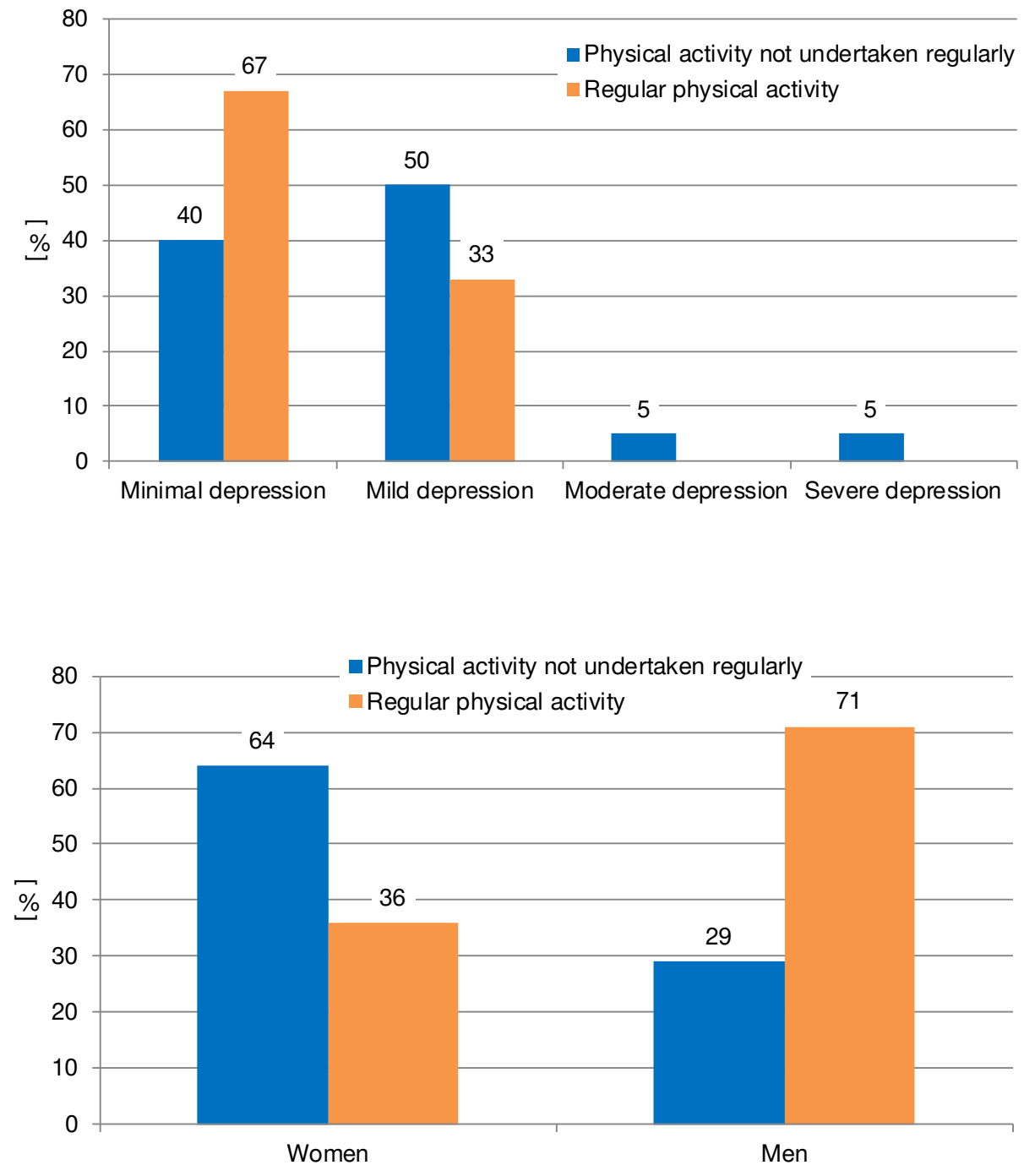

Figure 4. Regular physical activity and level of mood disorders
Figure 5. Regular physical activity and gender 
the results of surveys conducted among students of the same university in 2008 and 2014, one can observe that the incidence of mild depressive disorders has almost doubled.

In 2008, Szczepańska et al. [12] studied mood and wellbeing among 483 students of the Faculty of Physiotherapy at the University of Physical Education in Wrocław. It was found that $20 \%$ of the respondents had depressive symptoms. Minor mood disorders were reported in 15\% and severe mood disorders in $5 \%$ of the studied population. It was also noted that during the university studies, the frequency of depressive symptoms increased. The lowest rate was observed among students of the first year of full-time studies $(15 \%)$; in subsequent years, the values increased to $17 \%$ in the third year and $21 \%$ in the fourth year of full-time studies. The highest number of students with depressive disorders were reported in the fifth (final) year of extramural studies (28\%). In 2014, 153 students in the fifth year of the same university were examined [8]. The results showed that $71 \%$ of students had no mood problems. The most frequently revealed symptoms of reduced mood among physiotherapy students were fears about the future, difficulties in making decisions, nervousness and irritability, changes in body weight, and blaming oneself.

Among the students of Cracow universities, suicidal thoughts were reported by $2.9 \%$ of students at the JagielIonian University, $4.1 \%$ of students at the Pedagogical Academy of Cracow, and $6.3 \%$ of students at the Cracow University of Technology [13]. Similar data can be found in a study by Adamiak et al. [14], where the mental condition of second- and sixth-year students at the Medical University of Lodz was compared with the mood of students at other Lodz universities. Depressive disorders were detected in 22\% of the investigated population.

Pietras et al. [15], when examining the level of depression among pedagogical students, estimated the occurrence of depression symptoms as about $11 \%$ of students at this faculty. The results were compared with the values obtained for students of economy, where mood disorders were observed in about $2.5 \%$ of respondents. Despite using the same research tool (BDI) in the present study and the above-mentioned reports, it is not possible to directly compare the results because there are significant discrepancies in the numbers of respondents in the studied groups. Nevertheless, the collected material confirms the trend that has been observed for years, namely of a steady increase in depressive disorders in the student population. This is in line with other findings, leading to predictions that by 2020 depression will be the second most common disease and by 2030 it will be the primary disease in the general population [16].

Unfortunately, worrying findings also concern regular physical activity. Only $40 \%$ of the surveyed students declared that they engaged in such activity on a regular basis (twice a week). This is a surprisingly low figure given that these were students of the University School of Physical Education and that promoting a healthy lifestyle is an integral part of their professional activity. Research conducted by Poręba et al. [17] showed that $11.4 \%$ of the surveyed students of Wrocław universities were physically active every day: over $25 \%$ exercised 3-4 times a week, about $45 \%$ exercised once or twice a week, and about $16 \%$ exercised less frequently than once a week. Against this background, extramural students of the Faculty of Physiotherapy at the University of Physical Education in Wrocław came out very poorly. Perhaps the reason for this lies in the life situation of those people, who, while studying extramurally, have to combine professional work with studies, and in many cases also with family responsibilities.
In 2015, Morga et al. [18] evaluated the level of stress among students of the Faculty of Physiotherapy at the University School of Physical Education in Wrocław. Regular exercise was declared by $65 \%$ and these were full-time students. The study showed a significantly higher level of stress in the group of inactive people compared with the physically active individuals. Similar conclusions concerning the relationship between the severity of mood disorders and physical inactivity were reported in earlier publications by Wrocław scientists [8, 19]. On one the other hand, Morowatisharifabad et al. [20] did not observe any significant association between the level of physical activity and the degree of depression.

Another aspect of the study was the relationship between mood and the sense of well-being and gender. It turned out that women struggled with depressive disorders more often than men. Kuehner [21] reported that depression occurred twice as often in women than in men over the course of life. The results of research by Jaworska et al. [8] show that women are a group more vulnerable to depressive disorders. A reduced mood or increased symptoms of depression were found in $31.6 \%$ of women and $19.5 \%$ of men. The research revealed that as many as half of the women surveyed had mild depression and $8 \%$ had symptoms of moderate or severe depression. A vast majority of men did not present mood disorders, although there were cases of mild depression. No moderate or severe depression was found in men. Gender as a factor influencing well-being turned out to be statistically significant.

Special attention should be paid to suicidal thoughts and tendencies reported by the examined students. In the research by Szczepańska et al. [12], 1\% of 433 students of the Faculty of Physiotherapy at the University School of Physical Education in Wrocław admitted that they had suicide intentions. If one considers those who think about suicide but would not be able to commit it, the percentage of students at risk of taking their own lives increases to $5.8 \%$. In Poland, the number of suicides is growing year by year; in 2018, more than 5000 people took their own lives [22]. The act of suicide is the second most common cause of death among 15-29-year-olds and one of the 3 main causes of death among 15-44-year-olds [16]. Therefore, one should be very vigilant about all the data on this subject and should not underestimate the information obtained.

Research has shown that financial situation also has an impact on the well-being and mood of young people. Students who described their economic condition as 'good' demonstrated depressive disorders of lesser intensity. Similar conclusions can be drawn from earlier studies by this team [19], who noted a very interesting correlation, namely, that students with a low level of well-being and poor economic situation were less likely to take up paid employment. The authors explained this fact as caused by the pessimistic creation of reality, which is one of the symptoms of depression. Subsequent research conducted at the same university confirmed the relationship between mood and well-being and financial resources: the better the financial standing of the respondents, the lower the level of depressive disorders [8].

The present study also examined whether the students would accept assistance of a psychologist/psychotherapist if they experienced symptoms of depression. The willingness to seek support from a specialist was declared by $80 \%$ of the respondents. The remaining $20 \%$ were of a different opinion and it was surprising to find that individuals in this group were characterized by lower mood and well-being levels and therefore should be the first to seek such support. Earlier 
reports from the same university indicated that $60 \%$ of students declared their willingness to accept a therapist's assistance in the case of personal problems [19], which demonstrates that students' awareness is increasing and that a potentially larger group of people would look for help if need be.

Further analysis of the obtained results showed that most of the respondents were planning to work in their trained profession. Previous research revealed that dissatisfaction with the chosen course of study significantly correlated with depressive symptoms and was the cause of unwillingness to work as a physiotherapist. However, as the authors explain, such results appeared mostly at the initial stage of the studies (first to third year), when the studied subjects were mostly theoretical, which could be a reason for disappointment and dissatisfaction with the chosen studies. Only in the following years of education, when the practical courses began, could the students more accurately sense the real character of their future profession [19].

Summing up the results of the conducted research, we may confirm with full responsibility that the problem of mood disorders in students of the Faculty of Physiotherapy is not only serious but also increasing year by year. The most alarming findings concerned extramural students, as was demonstrated in the results discussed in the present paper. It is important to make sure that, from the first years of study, compulsory courses include subjects that will help students to understand their own problems and seek specialist support as soon as the need arises. University authorities have also recognized the gravity of the problem and, since the academic year of $2018 / 2019$, students have been given the opportunity to receive free psychological consultations. This is all the more important in view of the fact that future physiotherapists will be working with sick people in need of care, so they will need to have adequate mental resources to support their patients; otherwise, they may very quickly suffer from occupational burnout syndrome.

\section{Limitations}

Our research also has limitations, such as a small group of students (only 7 men), a large age range (24-39 years), and the use of one standardized measuring tool (BDI). Therefore, in order to draw correct conclusions, we suggest enlarging the research group and applying the right gender balance.

The study group was small but included the entire year of extramural students. So far, at the Faculty of Physiotherapy of the University of Physical Education in Wrocław, only full-time students have been subject to similar studies. The studies had larger sample sizes of up to 120 people, who were much closer in age. The large age spread among the extramural students of the present study is not a methodological error but represents the actual state of affairs. Also, the fact that a significant proportion of these individuals (about $60 \%$ ) already work in the profession reflects the reality. The remaining $40 \%$ also work full-time. For many reasons, these students differ significantly from those studying on a daily basis, with one important difference being the low level of physical activity. Therefore, the authors of the paper decided to conduct research in this group of students for comparison with the existing results.

\section{Conclusions}

1. Among the extramural students of the Faculty of Physiotherapy, $49 \%$ were diagnosed with mild mood disorders and $6 \%$ with moderate or severe depression.
2. Low level of physical activity, female gender, and poor financial situation were significantly related to the severity of depressive symptoms in the examined group.

3. Owing to the high percentage of students with mood disorders, it is necessary to educate the student population in the area of prophylaxis and promotion of mental health, preferably from the first years of study.

\section{Disclosure statement}

No author has any financial interest or received any financial benefit from this research.

\section{Conflict of interest}

The authors state no conflict of interest.

\section{References}

1. Pużyński S. Recurrent affective disorders [in Polish]. In: Pużyński S, Rybakowski J, Wciórka J (eds.), Psychiatry [in Polish], vol. 2. Wrocław: Urban \& Partner; 2012; 305357.

2. World Health Organization. Impact of economic crises on mental health. Copenhagen: World Health Organization; 2011.

3. Ministry of Health. Programme of depression prevention in Poland for 2016-2020 [in Polish]. Warszawa: Ministry of Health; 2016.

4. Zegan M, Michota-Katulska E, Lewandowska M, Boniecka I. The role of physical activity in prevention and support for the treatment of obesity and type 2 diabetes [in Polish]. Med Rodz. 2017;4:273-278; doi: 10.25121/ MR.2017.20.4.273.

5. Centrum Badania Opinii Społecznej. Poles about their health and health-related behaviours and activities [in Polish]. Warszawa: Centrum Badania Opinii Społecznej; 2012.

6. Wiraszka G, Głuszek-Osuch M, Ptak W, Stępień RB. Preliminary evaluation of depression symptoms in adult high school students and the associated socio-demographic and environmental factors. Med Stud. 2019; 35(2):139-146; doi: 10.5114/ms.2019.86333.

7. Zhang M, Bridler R, Mohr C, Moragrega I, Sun N, Xu Z, et al. Early detection of the risk of developing psychiatric disorders: a study of 461 Chinese university students under chronic stress. Psychopathology. 2019;52(6):367377; doi: 10.1159/000505787.

8. Jaworska L, Morawska N, Morga P, Szczepańska-Gieracha J. Analysis of the prevalence of depressive symptoms among students of the Faculty of Physiotherapy, University School of Physical Education in Wroclaw in the context of career plans. Fizjoterapia. 2014;22(3):1022; doi: 10.1515/physio-2014-0007.

9. Jaeschke R, Siwek M, Grabski B, Dudek D. Comorbidity of depressive and anxiety disorders [in Polish]. Psychiatria. 2010;7(5):189-197.

10. Zawadzki B, Popiel A, Pragłowska E. Psychometric properties of the Polish version of the Aaron T. Beck's Depression Inventory BDI-II [in Polish]. Psychol Etol Genet. 2009;19:71-95.

11. Beck AT, Ward CH, Mendelson M, Mock J, Erbaugh J. An inventory for measuring depression. Arch Gen Psychiatry. 1961;4(6):561-571; doi: 10.1001/archpsyc.1961. 01710120031004.

12. Szczepańska J, Klin Z, Jaroszewska A, Ciesielski R. Mood disorders in student population of Faculty of Physiotherapy, Academy of Physical Education in Wrocław. Part 1. Fizjoterapia. 2008;16(3):69-78; doi: 10.2478/ v10109-009-0030-y. 
13. Kowalewski I. Characteristics of the health situation of students in terms of their psychosomatic efficiency in selected universities of Kraków [in Polish]. Eduk Stud Bad Inn. 2006;2(94):28-35.

14. Adamiak G, Świątnicka E, Wołodźko-Makarska L, Świtalska MJ. Evaluation of quality of life of medical students depending on the number and severity of depressive symptoms [in Polish]. Psychiatr Pol. 2004;38(4):631-638.

15. Pietras T, Witusik A, Panek M, Zielińska-Wyderkiewicz E, Kuna $\mathrm{P}$, Górski P. Intensity of depression in pedagogy students [in Polish]. Pol Merk Lek. 2012;32(189):163-166.

16. World Health Organization. Depression and other common mental disorders. Global health estimates. Geneva: World Health Organization; 2014.

17. Poręba R, Gać P, Zawadzki M, Poręba M, Derkacz A, Pawlas K, et al. Life style and cardiovascular risk factors among students of Wroclaw postgraduate schools. Pol Arch Med Wewn. 2008;118(3):102-109; doi: 10.20452/ pamw.326.

18. Morga P, Podborączyńska M, Jaworska L, Szczepańska-Gieracha J. The level of perceived stress among students of the University School of Physical Education in Wroclaw. Fizjoterapia. 2015;23(4):43-54; doi: 10.1515/physio-2015-0020.

19. Szczepańska J, Klin Z, Jaroszewska A, Ciesielski R. The analysis of factors associated with presence of depression symptoms among students of Faculty of Physiotherapy at Academy of Physical Education in Wroclaw. Part 2. Fizjoterapia. 2008;16(3):79-88; doi: 10.2478/ v10109-009-0031-x.

20. Morowatisharifabad MA, Movahed E, Farokhzadian J, Nikooie R, Rahaei Z, Bidaki R, et al. Depression and physical activity among HIV-positive people: integrated care towards 90-90-90. HIV AIDS Rev. 2019;18(2):131136; doi: 10.5114/hivar.2019.86377.

21. Kuehner $\mathrm{C}$. Why is depression more common among women than among men? Lancet Psychiatry. 2017; 4(2):146-158; doi: 10.1016/S2215-0366(16)30263-2.

22. Suicides since 2017 [in Polish]. Available from: http:// statystyka.policja.pl/st/wybrane-statystyki/zamachysamobojcze/63803,Zamachy-samobojcze-od2017-roku.html. 